\title{
FORMAÇÃO EM PSICOLOGIA E O CAMPO DA DESIGUALDADE SOCIAL: UM ESTUDO DOCUMENTAL
}

\author{
Ana Paula SALVATORI \\ Allan Henrique GOMES ${ }^{\text {ii }}$
}

\begin{abstract}
RESUMO
O presente estudo tem como objetivo analisar um percurso de pesquisas e práticas de um curso de psicologia realizadas no Sistema Único de Assistência Social (SUAS) de um município do sul do Brasil. Por meio da metodologia da pesquisa documental, foram analisados trabalhos de conclusão de curso e relatórios de estágio dos anos finais da graduação, realizados entre 2004 e 2018 em serviços da política pública referida. O tratamento documental, orientado sob a perspectiva da psicologia sócio-histórica, evidencia os rastros de uma prática profissional em construção na formação inicial, bem como os efeitos da aproximação da graduação ao campo da desigualdade social no período que compreende a implantação e consolidação da Política Nacional de Assistência Social no país.
\end{abstract}

PALAVRAS-CHAVE: Formação em Psicologia; Política Pública; Desigualdade Social.

\section{PSYCHOLOGY TRAINING AND THE SOCIAL INEQUALITY REALM: A DOCUMENTAL STUDY}

\begin{abstract}
This study aims to analyse the research and practice trajectory of a psychology course executed in the System of Social Assistence (SUAS) of a town in the South of Brazil. Graduation works and internship reports from the last years of graduation, achieved from 2004 to 2018 in the public policy mentioned, were analysed by means of documental research methodology. The documental treatment, oriented by the perspective of social and historical psychology, makes evident the traces of a professional practice which is built in the initial training, as well as the effects of the graduation approach to the social inequality realm in the period which comprises the implementation and consolidation of Social Assistence National Politics in the country.
\end{abstract}

KEYWORDS: Psychology Training; Public Policy; Social Inequality.

\footnotetext{
${ }^{\text {i }}$ Graduada em Psicologia pela Associação Catarinense de Ensino/Faculdade Guilherme Guimbala (ACE/FGG). E-mail: anapsalvatori@ yahoo.com.br - ORCID iD: https://orcid.org/0000-0003-2494-3057.

${ }^{\text {ii }}$ Doutorado em Psicologia pela Universidade Federal de Santa Catarina (UFSC). Professor na Universidade da Região de Joinville (PPGE/UNIVILLE) e na Associação Catarinense de Ensino/Faculdade Guilherme Guimbala (ACE/FGG). E-mail: allanhg@gmail.com - ORCID iD: https://orcid.org/0000-0001-5366-8600.
} 


\title{
FORMACIÓN EN PSICOLOGÍA Y EL CAMPO DE LA DESIGUALDAD SOCIAL: UN ESTUDIO DOCUMENTAL
}

\begin{abstract}
RESUMEN
El presente estudio tiene como objetivo analizar una serie de investigaciones y prácticas de un curso de psicología realizado en el Sitema Único de Asistencia Social (SUAS) de un municipio del sur de Brasil. Por medio de la metodología de investigación documental, fueron analisados trabajos de término de curso e informes de pasantías en los años finales de la graduación, realizados entre 2004 a 2018 en dependencia de la política pública referida. El tratamiento documental, orientado sobre una perspectiva de la psicología socio-histórica, revela los rastros de una práctica profesional en construcción en la formación inicial, así como los efectos de la aproximación de la graduación al campo de la desigualdad social en el periodo que comprende la implementación y consolidación de la Política Nacional de Asistencia Social en el país.
\end{abstract}

PALABRAS CLAVE: Formación en Psicología; Política Pública; Desigualdad Social.

\section{INTRODUÇÃO}

O berço de regulamentação da psicologia como profissão no Brasil foi marcado por um contexto de "suspensão dos direitos fundamentais" decorrentes do regime militar, que influenciou na caracterização da profissão como elitista e descolada das demandas sociais. A repercussão da ditadura atingiu também as academias de modo a controlar qualquer ato ou intenção ideológica que fosse ao desencontro do que estava sendo instituído no país naquele momento (YAMAMOTO; OLIVEIRA, 2010, p. 9).

Mediante o quadro crescente de exclusão social que demarcava essas transformações sociais e políticas do país, a psicologia passa a questionar-se a respeito da sua aproximação com "as reais necessidades da sociedade brasileira" (CONSELHO FEDERAL DE PSICOLOGIA, 2009, p. 30). Por conseguinte, o Conselho Federal de Psicologia (CFP), "sob o discurso do compromisso social, convoca a profissão a repensar suas práticas, tidas como anistóricas, descontextualizadas e descomprometidas" (OLIVEIRA; AMORIM, 2012, p. 560).

Diante deste cenário, Yamamoto e Oliveira (2010), ao relatarem a inserção e o percurso da psicologia no âmbito das políticas sociais, procuram explanar sobre o que de fato é considerado uma política social e a serviço de que elas são implementadas.

As políticas sociais têm sido [...] estudadas como estratégias estatais para a resolução de problemas sociais particularizados e sua eficácia discutida nos diversos setores aos quais elas se vinculam. Todavia, um tratamento adequado das políticas sociais nos marcos do modo de produção capitalista demanda a 
consideração das chamadas questões de fundo, ou seja, os fundamentos na esfera do Estado para a definição das políticas públicas. E essa tarefa requer a remissão à chamada "questão social" (YAMAMOTO; OLIVEIRA, 2010, p. 10).

A questão social pode ser definida como a totalidade de problemas sociais, políticos e econômicos consequentes do capitalismo. O sistema capitalista alterou a lógica do trabalho e do consumo e seus efeitos manifestaram-se com o "crescimento da população e da urbanização". As expressões da desigualdade social acentuavam-se, pois, "a concentração da população nas áreas urbanas trouxe consigo problemas de assistência, educação, habitação, saneamento básico, de infraestrutura e tantos outros" (YAMAMOTO; OLIVEIRA, 2010, BULLA, 2003, p. 5) que atingiram as camadas menos favorecidas nessa lógica do consumo.

A precarização da vida, decorrente dessa nova organização econômica, revela que a desigualdade social perpassa questões de ordem material. Sawaia (2009, p. 369) nos ajuda a compreender esse fenômeno como uma "ameaça permanente à existência". Ao debruçar-se sobre as relações entre psicologia e desigualdade social, Sawaia $(2009,2012)$ nos apresenta o conceito de sofrimento ético-político, que retrata justamente essa condição de ser desfavorecido, injustiçado, considerado inferior. Ainda segundo a autora, às vidas em vulnerabilidade social não interessa "qualquer sobrevivência, mas uma específica, com reconhecimento e dignidade" (SAWAIA, 2012, p. 116).

Diante desse cenário e do compromisso assumido enquanto classe profissional, a psicologia inseriu-se em espaços não antes ocupados. Um dos exemplos sinalizado como relevante é o próprio Sistema Único de Saúde (SUS), que oferece um modelo de referência para a política na qual nos debruçaremos. A saúde, juntamente com a previdência social e a assistência social formam os três pilares da seguridade social prevista pela Constituição da República Federativa do Brasil, de 1988 (YAMAMOTO; OLIVEIRA, 2010).

A consolidação do Sistema Único de Assistência Social (SUAS) se deu por intermédio de diversos marcos históricos no âmbito da proteção e garantia de direitos no país. A partir da Constituição de 88 “o Brasil vivenciou a implementação de legislações no âmbito da proteção social (Estatuto da Criança e do Adolescente; Lei Orgânica da Assistência Social; Estatuto do Idoso; entre outras)" que oportunizaram, em 2004, a criação da Política Nacional de Assistência Social (PNAS). O SUAS, por sua vez, consolidou-se um ano depois, em 2005, e os serviços 
socioassistenciais passaram a receber as devidas organização, sistematização e regulamentação (ANDRADE et al., 2017, p. 230).

Consideram-se marcos históricos porque anteriormente a forma de se prestar assistência aos pobres carregava um viés assistencialista, de benevolência, que reforçava "práticas clientelistas, patrimonialistas" (FLORENTINO; MELO, 2017, p. 5) e não ofertava, de fato, o acesso aos direitos e à proteção social. Com a PNAS e o SUAS, essas ofertas passaram a estruturar-se em níveis de complexidade, de modo a atender todos os cidadãos que possuem seus direitos violados, ou sofrem ameaça de, a partir da atuação de ações interventivas e preventivas (FLORENTINO; MELO, 2017).

A PNAS divide os níveis de atenção em Proteção Social Básica (PSB), que busca a prevenção da violação de direitos por meio do fortalecimento dos vínculos familiares e comunitários (e tem como equipamento de referência o Centro de Referência de Assistência Social - CRAS) e Proteção Social Especial (PSE), destinada a famílias e indivíduos que se encontram em situação de risco social e/ou pessoal, com ameaça ou comprovação de direitos violados "por ocorrência de abandono, maus tratos físicos e, ou psíquicos, abuso sexual, uso de substâncias psicoativas, cumprimento de medidas sócio-educativas, situação de rua, situação de trabalho infantil, entre outras" (BRASIL, 2004, p. 37).

A Proteção Social Especial é estruturada em média e alta complexidade. Na primeira, os vínculos familiares e/ou comunitários ainda estão preservados, e os equipamentos de referência são o Centro de Referência Especializado de Assistência Social (CREAS) e Centro de Referência Especializado para pessoas em situação de rua (Centro POP). A alta complexidade, por sua vez, caracteriza-se pelo esgotamento desses recursos (familiares e comunitários), tornando o acolhimento institucional a medida mais cabível no que se refere à oferta de uma proteção integral (BRASIL, 2004).

A inserção das psicólogas ${ }^{1}$ nas equipes de referência de assistência social passa a ser obrigatória a partir da resolução 017/11 do Conselho Nacional de Assistência Social, pois entende-se que os recursos humanos neste contexto são essenciais para atender as particularidades do público assistido, bem como atingir os objetivos da própria política (FLORENTINO; MELO, 2017). Inicia-se, então, uma série de desafios relacionados à atuação da psicologia no que diz respeito não somente às suas contribuições neste setor, como também 
suas especificidades em relação às outras categorias profissionais que compõem as equipes, como o serviço social, por exemplo.

Esses entendimentos sobre a profissão foram fundamentais para que se questionasse o perfil das psicólogas que estavam se formando, uma vez que a formação precisa acompanhar as transformações sociais do contexto, pois "para que uma profissão assuma para si a proposta de enfrentar a sociedade desigual e injusta [...] é preciso que ela rompa com suas próprias amarras históricas" (SENRA; GUZZO, 2012, p. 296). Durante mais de quarenta anos, os cursos de psicologia seguiam um currículo mínimo instituído pelo parecer no 403 de 19/12/1962, que estabelecia três terminalidades para o curso: licenciatura, bacharelado e formação de psicóloga (o) (CFP, 2018).

Diante desse cenário, uma série de inquietações sobre a formação em psicologia passou a ocupar o "Sistema Conselhos, associações científicas e todos os atores da formação" a partir da década de 1990 (CFP, 2018, p. 8). Tais discussões, em conjunto com a promulgação da Lei n 9.394 de 20/12/1996 - Lei de Diretrizes e Bases da Educação Nacional, resultaram na instituição das Diretrizes Curriculares Nacionais (DCNs) para os cursos de psicologia, por meio da Resolução n 8 de 07/05/2004.

As DCNs de 2004 são reflexo e resposta à insuficiência do currículo mínimo diante das novas necessidades da conjuntura nacional, como as

mudanças sociais, o grande aumento do número de cursos e consequentemente de profissionais, a abertura democrática do país, a inserção de psicóloga (os) em novos campos de atuação, em especial nas políticas públicas, o contato profissional com uma população mais heterogênea, a necessidade de que a profissão se comprometesse com as condições e necessidades da população brasileira (CFP, 2018, p. 17).

A nova proposta curricular busca não indicar somente "disciplinas e conteúdos específicos" como fazia o currículo mínimo, mas desenvolver conhecimentos, competências e habilidades a partir de eixos estruturantes que entendem "o fenômeno psicológico como multideterminado e histórica e culturalmente contextualizado" (CFP, 2018, p. 17). As DCNs buscam reconhecer a psicologia na sua diversidade teórico-metodológica, prática e de contextos de inserção.

Os objetivos da presente pesquisa foram formulados em virtude desses fatos mencionados. A proposta é analisar um percurso de pesquisas e práticas de um curso de 
psicologia no âmbito do Sistema Único de Assistência Social (SUAS). Com metodologia da pesquisa documental, foram coletados e analisados trabalhos de conclusão de curso e relatórios de estágio realizados por acadêmicos do quarto e quinto ano em serviços da Secretaria Municipal de Assistência Social de um município do sul do Brasil, de 2004 a 2018.

\section{MÉTODO}

O presente artigo é resultado de uma pesquisa documental, metodologia de coleta e análise de dados caracterizada pelo tratamento de informações até então não consideradas fontes de consulta acerca de um determinado conhecimento (RAUPPY; BEUREN, 2006). Este procedimento mostra-se relevante, pois possibilita "acrescentar a dimensão do tempo à compreensão social" (SÁ-SILVA; ALMEIDA; GUINDANI, 2009, p. 2), tornando o documento inteligível diante da problemática escolhida. Sá-Silva, Almeida e Guindani (2009) apontam como condição necessária para a análise documental uma interpretação e inferência nos documentos, de modo que eles forneçam informações sobre o que se propõe estudar.

A partir do objetivo de analisar a formação em psicologia no campo da desigualdade social, os documentos definidos como amostra da pesquisa em questão foram trabalhos de conclusão de curso, relatórios de estágio do campo educacional ${ }^{2}$ e relatórios de estágio de psicologia clínica de um curso de psicologia, realizados entre os anos de 2004 e 2018, no âmbito do Sistema Único de Assistência Social (SUAS) de um município do sul do Brasil. Foram selecionadas as pesquisas e práticas realizadas em instituições governamentais da Proteção Social Básica, entidades que oferecem o Serviço de Convivência e Fortalecimento de Vínculos (BRASIL, 2009), instituições governamentais da Proteção Social Especial de média complexidade e instituições privadas da alta complexidade. No total, 94 documentos cumpriram com os critérios de inclusão.

Importante mencionar que esse universo de 94 documentos contempla 292 graduandos, considerando que a autoria dos textos por vezes é individual, em dupla e até em grupos com seis integrantes. Vale destacar, também, que o curso de psicologia em questão exige a produção de relatório para três modalidades de estágio, mas somente duas foram contabilizadas pela presente pesquisa. Essa terceira modalidade refere-se ao estágio de psicologia organizacional, prática que acontece majoritariamente em instituições do âmbito privado. A estrutura dos 
documentos sofreu algumas modificações no decorrer dos anos. Os trabalhos de conclusão de curso, por exemplo, deixaram de ser organizados pelo modelo de monografia e passaram a ser artigos científicos a partir de 2008 .

O acervo dos documentos é realizado por um laboratório da instituição e o acesso foi concedido pelos profissionais responsáveis por ele. Foi possível identificar, no local, a falta de um protocolo de entrega e arquivamento por parte dos responsáveis. Esse fato comprovou-se quando, por exemplo, trabalhos de conclusão de curso do ano de 2012 não puderam ser localizados. Também recorremos ao arquivo morto da instituição para encontrar outros documentos (relatórios de estágio do campo educacional de 2004 a 2008) que não estavam no local citado.

Após a seleção dos documentos que cumpriram com os critérios de inclusão na pesquisa (primeira etapa da investigação), foi realizado um levantamento das informações para uma primeira verificação do panorama e dinâmica do objeto em estudo. Nesta segunda etapa, os pesquisadores atentaram-se, além dos locais das pesquisas e intervenções, também para os seguintes aspectos: ano, autores(as), professores(as) orientadores(as), metodologias de pesquisa e/ou intervenção, temáticas e/ou público-alvo e a menção ao Sistema Único de Assistência Social. Tais aspectos foram tabulados em três arquivos, um para cada modalidade de documento (trabalhos de conclusão de curso - TCCs; estágio educacional; estágio clínica) possibilitando visualizações em gráficos e tabelas, mobilizando, dessa forma, os primeiros ensaios analíticos.

Tendo em vista o objetivo de analisar pesquisas e práticas de um curso de psicologia, durante determinado intervalo de tempo, realizadas em uma política pública específica, foi fundamental para todo processo de pesquisa a elaboração de um quadro documental de legislações, resoluções, normas operacionais e referências técnicas que contemplassem a história da profissão, da formação e do próprio SUAS. Este quadro privilegiou as referências oficiais, sobretudo, aquelas publicadas pelo Conselho Federal de Psicologia.

A relação entre documentos em investigação e documentos de referência, que apontam para a presença da profissão na política pública no contexto da análise, permitiu o tratamento documental, terceira etapa da análise. Corsetti (2006, p. 36) aponta que o "cruzamento entre fontes que se complementam", ou seja, a aproximação do quadro referencial e os documentos selecionados, possibilita uma compreensão contextualizada das informações da pesquisa. Nesta etapa o acervo em análise é acessado não somente pelos aspectos definidos a priori, mas 
também pelas minucias dos próprios documentos, evidenciando o caráter qualitativo do processo documental.

No tratamento documental, teve-se como critério eleger categorias de análise que retratassem os achados de pesquisa. Spink (2013, p. 112) aponta que a análise documental oferece o conhecimento "do universo de possibilidades e da densidade e variedade" de elementos cotidianos - o autor sinaliza como maior desafio "aprender a ouvir" (p. 112) o material escolhido. O efeito deste processo é uma nova objetivação documental, a saber, a escrita e a comunicação dos resultados da pesquisa.

Considerando todo o empreendimento da pesquisa, do objetivo principal ao tratamento documental, os resultados estão categorizados em três temáticas: (a) Aspectos de um percurso da psicologia no SUAS; (b) O encontro com a desigualdade social no campo da Proteção Social Básica; (c) A psicologia no âmbito das violações de direitos da criança e do adolescente.

\section{ASPECTOS DE UM PERCURSO DA PSICOLOGIA NO SUAS}

Após a etapa de coleta de dados, os documentos foram organizados em tabelas e gráficos de diferentes categorias. Em termos gerais, contabilizamos 94 produções que cumpriram com os critérios de inclusão, sendo estas 36 trabalhos de conclusão de curso, 37 relatórios de estágio do campo educacional e 21 relatórios de estágio de psicologia clínica relacionados aos serviços da Assistência Social, entre o período de 2004 e 2018.

Apesar de o número de relatórios de psicologia clínica ser o menor em relação às outras modalidades, tendo em vista certa equidade entre o número de trabalhos de conclusão de curso e relatórios do campo educacional, considerou-se significativo que 21 documentos tenham apresentado registros de atendimentos para adultos, crianças e adolescentes em serviços do SUAS. Essa surpresa é efeito de uma discussão sobre fazer clínica na Assistência Social, em razão das orientações sobre a não oferta da psicoterapia neste setor (CFP, 2016).

Entende-se que até a entrada da psicologia nas políticas públicas, "não existia outra referência sobre o significado de atender as pessoas" que não fosse pela psicoterapia (OLIVEIRA, 2009, p. 107). No entanto, é relevante nos atentarmos para a própria nomenclatura do estágio juntamente com a noção de clínica. A clínica não deve ser reduzida à prática 
psicoterapêutica, mas entendida como um método de trabalho que, inclusive, não é exclusivo da psicologia.

Devido à história da formação, por muito tempo os currículos pautavam-se na hegemonia de disciplinas que se estruturavam pela Psicanálise, pelo Humanismo e Behaviorismo. Inclusive, os alunos que não se identificavam com tais linhas teóricas, de certa forma, eram "desqualificados". Essa condição resulta em uma limitação nas possibilidades de se fazer $p s i$, que marca a ocupação de espaços como os do SUAS, por exemplo (OLIVEIRA, 2009, p. 121).

Ao passo que nos ajuda a refletir sobre a não substituição da psicoterapia em situações nas quais ela é indispensável, Oliveira (2009) afirma a ação clínica - entendendo-a pela tríade: avaliação, intervenção e acompanhamento - como pertinente nos mais diversos contextos. $\mathrm{O}$ autor também aponta a necessidade de formar psicólogas "para o exercício da ação clínica [...] independente das linhas teóricas" e

ampliar sua capacidade de análise dos contextos; desenvolver sua capacidade de articulação de variáveis para o exercício de um diagnóstico; treinar as várias metodologias de diagnósticos - individual, social, institucional, comunitários; aprender a fazer os registros de seus projetos de intervenção, bem como o manejo de várias tecnologias necessárias para intervir (OLIVEIRA, 2009, p. 122-123).

Diante disso, pode-se conjeturar que estágios e pesquisas no âmbito da Assistência Social podem possibilitar o desenvolvimento de tais habilidades, pois as demandas desses espaços exigem a saída dos modos tradicionais de se fazer psicologia. Os documentos analisados, então, revelaram uma crescente ocupação de estagiárias (os) e pesquisadoras (es) nos serviços do SUAS entre os anos de 2004 e 2018, conforme o gráfico 1. 


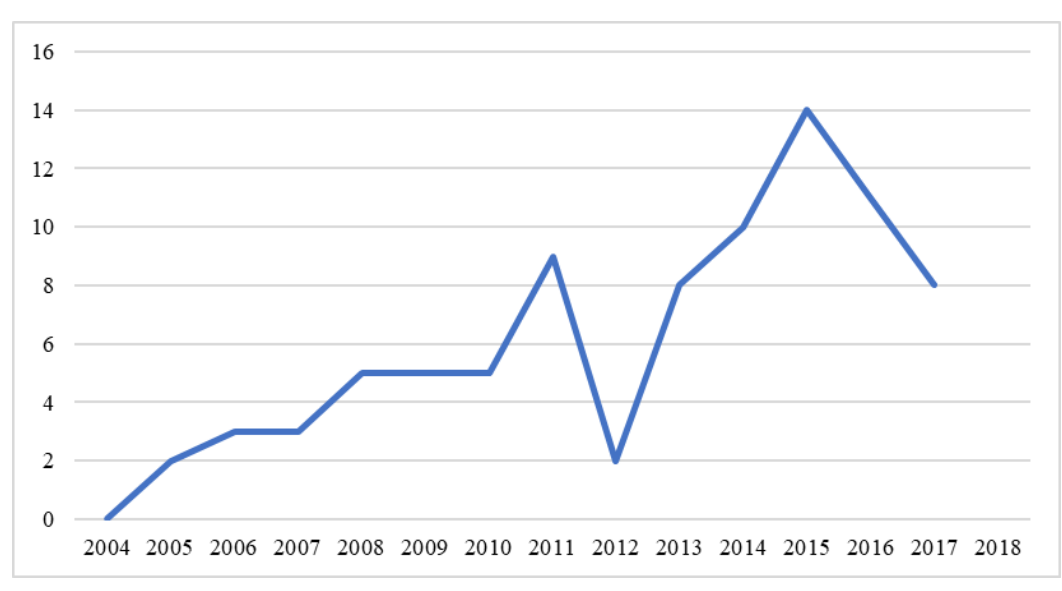

Gráfico 1 - Quantidade de documentos por ano Fonte: Produção da Pesquisa (2019).

$\mathrm{O}$ ano de 2015 destaca-se pelo maior registro de documentos, totalizando 14 pesquisas e/ou intervenções, seguido pelos anos de 2016 (11), 2014 (10) e 2017 (10), que também são relevantes nesse sentido. Compreende-se que esse aumento, com o passar dos anos, reflete uma prática que está sendo construída em concomitância pelos conselhos de representação da psicologia e pela própria política pública de Assistência Social. As publicações de referências técnicas para atuação das psicólogas em serviços do SUAS iniciaram-se em 2007, com o documento que orienta a prática nos CRAS, e seguem até 2017 - ano da última publicação, até então, do Centro de Referência Técnica em Psicologia e Políticas Públicas (CREPOP). Podese indicar que, em âmbito nacional, as discussões sobre a relação entre psicologia e SUAS não cessaram, da mesma forma o faz um curso de psicologia com suas experiências de pesquisa e estágio (BRASIL, 2004; CFP, 2016; CREPOP, 2007; 2012; 2013; 2017).

Fez parte, também, da categorização dos dados, contabilizar os documentos por níveis de complexidade. Os 36 trabalhos de conclusão de curso dividem-se em três realizados na Proteção Social Básica, 18 na Proteção Social Especial de média complexidade e 14 na Proteção Social Especial de alta complexidade. Os estágios do campo educacional aconteceram 12 vezes na PSB, 12 vezes na média complexidade e 13 vezes na alta. E os estágios de psicologia clínica, por sua vez, aconteceram seis vezes na média complexidade e 15 na alta. Não foram encontrados registros deste último em serviços da PSB.

A partir dos números apresentados, constatamos que os serviços da PSB são os menos frequentes no que diz respeito às pesquisas e práticas de um curso de psicologia. 15,9\% das pesquisas e dos estágios aconteceram nestes espaços, ao passo que 45,3\% aconteceram na alta 
complexidade, um expressivo número em relação às outras complexidades. Essa disparidade será discorrida nas categorias adiante. Vale apontar que um documento não fez parte desta divisão, pois cita em seu texto somente uma parceria com a Secretaria de Assistência Social do município, não caracterizando um serviço específico que possibilitasse identificar o nível de complexidade.

Por fim, outra categorização que fez parte do procedimento de análise dos dados foi a identificação das temáticas e/ou públicos-alvo de cada documento. Foi possível constatar sete grandes temáticas que contemplassem todos os documentos: infância e adolescência; famílias; mulheres; idosos; população em situação de rua e trabalhadores do SUAS. Entre estas, a de grande destaque foi a temática da infância e adolescência, que também será analisada com maior descrição posteriormente. Encontramos 16 TCCs, 26 relatórios do campo educacional e 18 relatórios de psicologia clínica que debruçaram-se sobre este público.

É pertinente destacar que os documentos cujas temáticas identificadas pelos pesquisadores como "famílias" ou "trabalhadores do SUAS" também possuem atravessamentos da infância e adolescência, como apontam alguns trabalhos de conclusão de curso: "Violência intrafamiliar" (SANTOS; KROEGER, 2011), "Pais sociais" (PEREIRA; PORSCH, 2011) e "Famílias acolhedoras" (BARRETO, 2016), assim como intervenções de estágio, que aconteceram com profissionais que atendem este público e tiveram como foco orientações sobre desenvolvimento infantil e aprendizagem.

\section{O ENCONTRO COM A DESIGUALDADE SOCIAL NO CAMPO DA PROTEÇÃO SOCIAL BÁSICA}

O arranjo dos serviços do Sistema Único de Assistência Social por níveis de complexidade possibilitou uma organização na oferta de atendimentos de acordo com as especificidades de cada situação. A Política Nacional de Assistência Social (2004, p. 92) cita que por "decorrência do impacto desses riscos no indivíduo e em sua família", exige-se que o processo de proteção seja estruturado em níveis de complexidade. De fato, oferecer proteção social diante da precarização da vida decorrente da desigualdade social é complexo (GOMES; ANDRADE; MAHEIRIE, 2017). 
É possível caracterizar como complexo, também, os desafios da formação em psicologia diante das demandas do SUAS. A complexidade em se entender de que forma o psicólogo atua e contribui para a transformação social no âmbito da Assistência Social é decorrente de uma série de modificações da psicologia como ciência e profissão. Já foi mencionado que até os anos 1980, no Brasil, a atuação da psicologia privilegiava um modelo tradicional de atendimento: a psicoterapia (MARTINS; MATOS; MACIEL, 2009). Esse histórico gerou uma "hipertrofia do modelo profissional, consagrado na figura do psicoterapeuta como profissional liberal" (OLIVEIRA, 2009, p. 121) e reverbera até os dias atuais, em espaços como os serviços da Proteção Social Básica, por exemplo.

Dos documentos coletados, como citado anteriormente, somente $15,9 \%$ das pesquisas e dos estágios aconteceram nos serviços da PSB: três trabalhos de conclusão de curso e 12 estágios do campo educacional. Esses números refletem uma trajetória de desafios e questionamentos que não somente os espaços formadores de psicólogos enfrentam, como também e principalmente a classe profissional atuante. É notório como as experiências referentes à pesquisa e estágio de um curso de psicologia caminham em consonância com a construção de uma prática em nível macro, ou seja, para a história recente da profissão no Brasil.

Oliveira et al. (2011) discorrem sobre as dificuldades encontradas pelos psicólogos na PSB, especificamente nos CRAS, tendo em vista que a psicoterapia - estratégia de intervenção mais relacionada à profissão - não deve ser adotada neste contexto, segundo orientações do Ministério do Desenvolvimento Social (BRASIL, 2009). Motta e Scarparo (2013, p. 234) evidenciam a necessidade, então, de "sair dos modelos tradicionais de atuação para uma atividade cada vez mais desafiadora, rica e criativa". A complexidade em se entender as especificidades da profissão na PSB resulta em tensionamentos cotidianos de trabalho.

Esses tensionamentos vêm sendo discutidos não somente pelos conselhos federal e regionais de psicologia, como também pela academia, uma vez que, por muito tempo, a formação em psicologia desencontrava-se das demandas sociais do país (OLIVEIRA et al., 2011, MOTTA; SCARPARO, 2013). Os números de documentos da presente pesquisa que referem-se à PSB - os menores em relação às outras complexidades - apontam para o que parece ser um território a ser explorado, e que, de fato, está sendo. Os estágios do campo educacional, neste contexto, iniciaram a partir de 2011 e tiveram sua maior concentração nos últimos três anos (2016 - 2018). 
Apesar de terem sido identificados somente três trabalhos de conclusão de curso em serviços da PSB, é imprescindível destacar uma produção de 2017 que analisa justamente a atuação de trabalhadores dos CRAS. Os pesquisadores se propuseram a ouvir os trabalhadores - entre estes, psicólogos - por meio de questionário e grupo focal, para analisar as problemáticas relativas a este campo de trabalho. Destaca-se, entre os resultados da pesquisa, os desafios do contato com a desigualdade social e a falta de uma formação, prévia, e principalmente, continuada, que qualifique a atuação nestes espaços (ANDRADE, 2017).

Um outro documento que podemos destacar, ainda nesta perspectiva, trata de um percurso de oficinas com a temática das relações étnico-raciais, realizado com profissionais do SUAS - entre os participantes, profissionais da PSB. Os resultados da intervenção apontaram para a escassez de discussões sobre temáticas como essa no âmbito da Assistência Social. As relações étnico-raciais encontram-se intimamente imbricadas com o campo da desigualdade social, e novamente, fora apontado o despreparo (em razão da falta de espaços de estudos) para com essas questões (NEVES, 2017).

A PSB, como novidade na implantação do SUAS, exige outros modos de atuação, não somente pela via do atendimento às violações de direitos. Exige que se pense em uma atuação distanciada dos modos pré-SUAS de fazer assistência social, pois, mesmo que evidente a implantação do SUAS como um marco no âmbito da garantia de direitos, entende-se que "política social não se faz somente por ato legislativo" (GOMES; ANDRADE; MAHEIRIE, 2017, p. 3).

A complexidade no encontro entre o profissional do SUAS e seu usuário está calcada em uma ordem que escapa às normas operacionais e referências técnicas de atuação. Os sujeitos que chegam aos serviços da PSB não encontram-se em situação de violências propriamente ditas - àquelas comumente associadas ao atendimento psicológico - mas "de uma lógica histórica e econômica desigual" (GOMES; ANDRADE; MAHEIRIE, 2017, p. 16) que organiza os modos de vida. Romper com essa lógica operante que marca histórias de sujeitos pela desigualdade social é uma tarefa árdua e, por vezes, incerta, mas existem possibilidades de amenizar os efeitos dela.

O histórico do assistencialismo que os serviços da Assistência Social interferem, principalmente, em espaços como o CRAS, uma vez que este equipamento tem como um de seus objetivos oferecer benefícios para o "alívio imediato da pobreza" (CREPOP, 2007, p. 24). 
No entanto, se faz imprescindível retomar as demais finalidades que a PSB possui nos territórios onde estão localizados: fortalecer vínculos familiares e comunitários em uma perspectiva emancipatória do sujeito de direitos (CREPOP, 2007).

Oliveira et al. (2011) apontam para esse desafio:

O trabalho com famílias visando à sua emancipação, organização e conscientização sobre seus direitos, exige um tipo de abordagem que não é apenas coletiva, é política. Essa postura não pode ser orientada por meio de manuais; faz parte de uma formação que, de fato, passa distante dos bancos acadêmicos ou das capacitações (OLIVEIRA et al., 2011, p. 147).

Ainda que as experiências de pesquisa e estágios no campo da PSB sejam poucas em relação às outras complexidades, os documentos revelaram a presença de estagiárias (os) e pesquisadoras (es) em CRAS por cinco vezes, e também um significativo trabalho do estágio do campo educacional em grupos de convivência de idosos por três anos consecutivos. Experiências como essas vão ao encontro da discussão de oportunizar ao acadêmico, no âmbito da formação em psicologia, "a capacidade de pensar as suas diferentes inserções e fazeres específicos a cada uma delas" (MARTINS; MATOS; MACIEL, 2009, p. 1039).

Ainda assim, aponta-se que, pelos documentos analisados, as pesquisas e estágios relacionados à PSB restringem-se aos serviços de convivência, práticas grupais e atividades neste sentido, enquanto discussões sobre território e sua pertinência no que se refere ao planejamento de ações mais assertivas aos públicos destinatários (OLIVEIRA et al., 2011) precisam avançar.

\section{A PSICOLOGIA NO ÂMBITO DAS VIOLAÇÕES DE DIREITOS DA CRIANÇA E DO ADOLESCENTE}

Assim como a quantidade de estagiárias (os) e pesquisadoras (es) de um curso de psicologia no âmbito da PSB caracterizou-se como um fato a ser analisado, os números da Proteção Social Especial (média e alta complexidade) também merecem desdobramentos. No total, foram encontrados 78 documentos relacionados a este contexto, divididos em 35 da média complexidade e 43 da alta. Desses 78 documentos, 53 possuem como temática de pesquisa ou público-alvo das intervenções as crianças e os adolescentes, ou seja, 68\% dos trabalhos realizados na PSE estão relacionados ao âmbito das violações de direitos deste público. 
A relação da psicologia com este contexto faz parte de uma série de marcos legais e desdobramentos históricos no que se refere à proteção aos direitos da criança e do adolescente. A própria concepção de infância passou por diversas transformações que acompanharam as necessidades econômicas e culturais de cada tempo e lugar. Até que se instituísse a Doutrina da Proteção Integral e, com ela, o Estatuto da Criança e do Adolescente, as crianças já foram consideradas desde pequenos adultos, inocentes, até "investimento lucrativo para o Estado, [...] uma força de produção que traria lucros a longo prazo" (COSTA, 2010, p. 12). Muito se caminhou até serem concebidas como pessoas em condição peculiar de desenvolvimento (BRASIL, 1990).

Dos 53 documentos relativos à PSE de crianças e adolescentes, 34 são pesquisas ou intervenções em instituições de acolhimento. É um expressivo número de graduandos inseridos em atividades na alta complexidade, especialmente em uma entidade da rede privada, que recebe financiamento da Secretaria de Assistência Social do município, a qual foi local de estágio e campo de pesquisas de TCC por aproximadamente 30 vezes.

Arthur Moncorvo Filho (1926 apud ZANIANI; BOARINI, 2011, p. 275) aponta que as primeiras demonstrações de “'interesse público' pela proteção das crianças no Brasil” foram as instituições de acolhimento. No entanto, essas primeiras casas (Santa Casa de Misericórdia, Casas dos Expostos, Roda etc.) não supriam as reais demandas das "crianças abandonadas", pois tinham como preocupação primordial o viés religioso em detrimento dos cuidados com saúde, higiene e alimentação.

a desobediência aos preceitos básicos de higiene era causa evidente da maioria das mortes e se estas instituições não primavam pela higiene, tampouco pela moral. Para se ter ideia da dimensão da calamidade, em treze anos, deu entrada nas Casas dos Expostos cerca de doze mil crianças e, destas, sobreviveram apenas mil (ZANIANI; BOARINI, 2011, p. 275).

As autoras discorrem sobre como as mudanças "na forma de produção de vida (o trabalho escravo sendo gradativamente substituído pelo assalariado)" (ZANIANI; BOARINI, 2011, p. 276) no Brasil republicano contribuíram para que a criança fosse vista como "força potencial de trabalho", tornando a religião e a caridade não mais suficientes para assistir essa infância abandonada e vulnerável. O discurso científico, então, ganha lugar pois seu conhecimento garante saúde física, mental e principalmente, maior sobrevivência às crianças. 
O interesse pelo acolhimento institucional de crianças e adolescentes percebido nos documentos coletados abrange especificidades que coincidem com a trajetória histórica dessas instituições. Doze projetos de estágio do campo educacional tiveram como foco das intervenções o desenvolvimento motor, cognitivo e dificuldades de aprendizagem das crianças, bem como orientações às equipes das instituições sobre essas temáticas.

Costa (2010) explica que a psicologia ganhou espaço nessas discussões, juntamente com áreas de estudo como a pediatria e pedagogia, pois um cenário de investimento à infância expandiu-se gradativamente. Mediante esses avanços, destacou-se as implicações da psicologia sobre o "desenvolvimento psicossocial" infantil, as quais buscam minimizar "os efeitos da desproteção social que acometem no Brasil milhares de crianças e adolescentes" (ZANIANI; BOARINI, 2011, p. 279). Tais contribuições são evidentes nas pesquisas e práticas de um curso de psicologia, pois existem registros desses trabalhos ao longo de 12 anos, de 2006 a 2018.

Outro ponto de interesse a respeito das crianças e adolescentes institucionalizados são os aspectos psicológicos relativos ao processo de acolhimento e adoção. Os atendimentos dos estágios de psicologia clínica realizados nestas instituições juntamente com alguns trabalhos de conclusão de curso como "A história de um menino abrigado" (SIEWERT; SIEGLE, 2005), "As concepções de crianças e adolescente sobre o estar em abrigo" (KOSER; SOUZA; MULLER, 2007), "O olhar do pré-adolescente e do adolescente institucionalizado sobre família, abrigo, adoção e suas expectativas de futuro" (SILVEIRA; REINKE; 2009) demonstram uma preocupação em oferecer um espaço de fala para esses sujeitos. Essa preocupação é efeito da nova concepção de criança e adolescente advinda do ECA.

Leoncio (2009, p. 22) aponta a relevância da expressão 'sujeito de direitos', presente no Artigo 15 do Estatuto:

uma concepção da criança e do adolescente como indivíduos autônomos e íntegros dotados de personalidade e vontade próprias, que na sua relação com o adulto não podem ser tratados como sujeitos passivos, subalternos ou meros 'objetos', devendo participar das decisões que lhe dizem respeito, sendo ouvidos e considerados de acordo com suas capacidades e o grau de desenvolvimento.

O ECA influenciou também o atendimento ao adolescente em conflito com a lei, público de pesquisa e intervenção de pesquisas e estágios por seis vezes, conforme os documentos analisados. Anterior ao Estatuto, as crianças e os adolescentes eram assistidos pela normativa da Doutrina da Situação Irregular, que instituiu o Código de Menores. Essa perspectiva 
caracterizava-se por uma "tutela judicial que assegurava o controle e a vigilância, em especial aos segmentos pobres" (CREPOP, 2012, p. 29). O ECA vem para romper com tal perspectiva e organizar medidas de caráter socioeducativo para àqueles que cometeram algum ato infracional.

O primeiro registro de pesquisa com adolescentes neste contexto data o ano de 2006, o mesmo ano de publicação do Sistema Nacional de Atendimento Socioeducativo (SINASE). O SINASE vem para organizar todo o processo de atendimento socioeducativo em sua dimensão política, pedagógica, financeira e administrativa. Em 2012, a partir da Lei $\mathrm{n}^{\circ} 12.592$, o SINASE configura-se como um subsistema dentro do Sistema de Garantia de Direitos da Criança e do Adolescente (SDG) (CREPOP, 2012). O SDG contempla políticas públicas como a educação, a segurança pública, o SUS e também o SUAS. É no SUAS, especificamente na média complexidade, que os adolescentes cumprem as medidas socioeducativas em meio aberto, e foi neste contexto que encontramos documentos de pesquisa e intervenção.

Dois seis documentos relativos a esse público, destacamos duas produções: um trabalho de conclusão de curso e um estágio do campo educacional, que refletem do mesmo modo os efeitos do ECA no atendimento aos adolescentes em conflito com a lei. No primeiro, buscouse compreender os sentidos do território atribuídos por esse público, através de atividades com fotografia (FELÍCIO, 2017); e neste último, os estagiários inseriram-se no serviço de medidas socioeducativas e elaboraram uma proposta de atendimento: atendimentos em grupos, por meio de oficinas temáticas (WITT et al., 2018).

Vivências no contexto das medidas socioeducativas proporcionam o exercício de reinventar práticas da psicologia, para que as intervenções não sejam feitas pelo viés de um ajustamento de conduta. As ações estipuladas pelo ECA e pelo SINASE exigem um enfrentamento ao estigma da marginalização que esse público carrega, decorrente, novamente, dos efeitos da desigualdade social (COSTA; ASSIS, 2006, MALVASI, 2011).

Por fim, ainda nesta perspectiva, outra situação verificada nos documentos da presente pesquisa são os casos de violência sexual atendidos pelo estágio de psicologia clínica, na média complexidade. É evidente a relevância da psicologia em tais situações, tendo em vista as "sérias consequências, como o comprometimento do desenvolvimento físico, psicológico e social" (CFP, 2009, p. 36) presentes nos sujeitos que vivenciaram essa violência. Apesar dos desafios em relação à atuação no contexto da Assistência Social, conforme já discorrido, vale ressaltar 
que três documentos desse estágio registram intervenções em grupos, como alternativa de atendimento para casos como esses.

O CFP (2009, p. 34) aponta que é um consenso considerar como complexo o "fenômeno da violência contra crianças e adolescentes", e por este motivo, são evidentes os desafios da atuação. No entanto, é preciso entender que as referências de atuação são construídas mediante a própria prática, tendo em vista que as causas das violações de direitos deste público são multideterminadas. São por estas razões que as experiências de pesquisas e estágios em espaços como os do SUAS contribuem para a formação de psicólogas que consideram que a "produção de conhecimento deve ser compreendida como dialética, e teoria e prática estão sempre em mútua construção" (CFP, 2009, p. 43).

\section{CONCLUSÃO}

A consolidação da psicologia como ciência e profissão no Brasil transitou por transformações nas esferas política e legislativa que exigiram da classe profissional uma atuação mais compromissada e contextualizada com as demandas sociais. O contato da profissão com a desigualdade social foi, por muito tempo, velado, tendo em vista o histórico do público que conseguia acessar os serviços psicológicos. Mediante a inserção da psicologia nas políticas públicas, os espaços formadores também foram exigidos neste sentido.

A partir da análise dos documentos, foi possível observar que as atividades de pesquisa e estágio de um curso de psicologia nos serviços do SUAS encontram-se em crescente construção. Por tratar-se de uma política pública relativamente nova, a atuação da psicologia no SUAS ainda é permeada de questionamentos e desafios, no que tange às contribuições e especificidades da profissão. Mediante a análise documental realizada, percebe-se que essa condição reflete, da mesma forma, nos espaços da formação.

Um dos desafios expressos nos documentos é acerca da atuação no campo da Proteção Social Básica. Os números de pesquisas e estágios nestes serviços (os menores em relação às outras complexidades) apontam para uma prática profissional que está em desenvolvimento. As especificidades dos sujeitos usuários da PSB exigem dos (futuros) profissionais uma atuação reinventada, pelo viés do fortalecimento de vínculos e acesso aos direitos. Neste sentido, os 
documentos revelaram um significativo trabalho de práticas grupais em serviços de convivência com crianças, adolescentes e idosos.

Do mesmo modo, a expressiva presença de pesquisas e estágios no campo das violações de direitos da criança e do adolescente mostrou-se relevante. Apesar de não ser novidade a atuação da psicologia em defesa desse público, a produção acadêmica analisada evidenciou os reflexos do ECA nas percepções sobre infância e adolescência, e como essas refletiram na atuação da psicologia neste contexto. Nos documentos que são objeto deste estudo, as contribuições perduraram ao longo de quinze anos, apontando a pertinência da profissão no cenário de garantia de direitos e proteção social para crianças e adolescentes.

Finalmente, é possível concluir que as experiências formativas no âmbito das políticas públicas se constituem historicamente relevantes. No caso deste estudo, a envergadura documental aponta que a pertinência de práticas e pesquisas continuadas possibilita que a desigualdade social possa ser tematizada na graduação de psicologia. Dessa maneira, as pesquisas e os estágios acabam por transversalizar a discussão das políticas públicas no projeto curricular, especialmente, quando realizadas de forma sistemática e mediante parcerias sucessivas, pois assim, garantem um modo articulado de formação no campo da desigualdade social.

\section{REFERÊNCIAS}

ANDRADE, Letícia de. Problemáticas constitutivas na atuação nos CRAS: tensões relativas a um campo de trabalho. 2017. Trabalho de Conclusão de Curso (Bacharelado em Psicologia) - Faculdade Guilherme Guimbala, Joinville, 2017.

ANDRADE, Letícia de et al. Percursos e experiência no Sistema Único de Assistência Social em Joinville/SC. Revista de Ciências Humanas, Florianópolis, v. 51, n. 1, p. 230-248, janjun. 2017. Disponível em: https://periodicos.ufsc.br/index.php/revistacfh/article/view/21784582.2017v51n1p230/34483. Acesso em: 23 ago. 2019.

BARRETO, Janaína Pereira. Encontro da obra de Viktor Frankl com famílias

acolhe(dor)as. 2016. Trabalho de Conclusão de Curso (Bacharelado em Psicologia) Faculdade Guilherme Guimbala, Joinville, 2016.

BRASIL. Lei no 8.069, de 13 de julho de 1990. Dispõe sobre o Estatuto da Criança e do Adolescente e dá outras Providências. Brasília, DF, 1990. 
BRASIL. Lei no 9.394, de 20 de dezembro de 1996. Estabelece as Diretrizes e Bases da Educação Nacional. Brasília, DF, 1996.

BRASIL. Ministério do Desenvolvimento Social e Combate à Fome. Política Nacional de Assistência Social - PNAS. Brasília, DF, 2004.

BRASIL. Ministério do Desenvolvimento Social e Combate à Fome. Orientações Técnicas Centro de Referência de Assistência Social - CRAS. Brasília, DF, 2009.

BULLA, Leonia Capaverde. Relações sociais e questão social na trajetória histórica do serviço social brasileiro. Revista Virtual Textos \& Contextos, n. 2, 2003. Disponível em: http://revistaseletronicas.pucrs.br/fass/ojs/index.php/fass/article/view/947/727. Acesso em: 01 out. 2019.

CENTRO DE REFERÊNCIA TÉCNICA EM PSICOLOGIA E POLÍTICAS PÚBLICAS (CREPOP). Referência Técnica para atuação do(a) psicólogo(a) no CRAS/SUAS. Conselho Federal de Psicologia, Brasília, DF, 2007.

CENTRO DE REFERÊNCIA TÉCNICA EM PSICOLOGIA E POLÍTICAS PÚBLICAS (CREPOP). Referências Técnicas para Atuação de Psicólogas(os) em Programas de Medidas Socioeducativas em Meio Aberto. Conselho Federal de Psicologia, Brasília, DF, 2012.

CENTRO DE REFERÊNCIA TÉCNICA EM PSICOLOGIA E POLÍTICAS PÚBLICAS (CREPOP). Referências Técnicas para atuação de psicólogas(os) nos Centros de Referências Especializado de Assistências Social - CREAS. Conselho Federal de Psicologia, Brasília, DF, 2013.

CENTRO DE REFERÊNCIA TÉCNICA EM PSICOLOGIA E POLÍTICAS PÚBLICAS (CREPOP). Relações Raciais - Referências Técnicas para atuação de psicólogas(os). Conselho Federal de Psicologia, Brasília, DF, 2017.

CONSELHO FEDERAL DE PSICOLOGIA (CFP). Serviço de Proteção Social a Crianças e Adolescentes Vítimas de Violência, Abuso e Exploração Sexual e suas famílias: referências para psicólogos. Brasília, DF, 2009.

CONSELHO FEDERAL DE PSICOLOGIA (CFP). Psicologia: uma profissão de muitas e diferentes mulheres. Brasília, DF, 2013.

CONSELHO FEDERAL DE PSICOLOGIA (CFP). Nota técnica com parâmetros para atuação das(os) profissionais de psicologia no âmbito do Sistema Único de Assistência Social (SUAS). 2016.

CONSELHO FEDERAL DE PSICOLOGIA (CFP). Ano da formação em Psicologia: Revisão das diretrizes curriculares nacionais para os cursos de graduação em Psicologia. 2018. 
CONSELHO NACIONAL DE EDUCAÇÃO. Resolução Nº 8, de 7 de maio de 2004. Institui as Diretrizes Curriculares Nacionais para os cursos de graduação em Psicologia. 2004.

CORSETTI, Berenice. A análise documental no contexto da metodologia qualitativa: uma abordagem a partir da experiência de pesquisa do Programa de Pós-Graduação em Educação da Unisinos. UNIrevista, v. 1, n. 1, p. 32-46, jan. 2006. Disponível em:

http://gephisnop.weebly.com/uploads/2/3/9/6/23969914/a_anlise_documental_no_contexto_d a_pesquis_qualitativa.pdf. Acesso em: 14 maio 2019.

COSTA, Cláudia Regina Brandão Sampaio Fernandes da; ASSIS, Simone Gonçalves de. Fatores protetivos a adolescentes em conflito com a lei no contexto socioeducativo.

Psicologia \& Sociedade, v. 18, n. 3, p-74-81, set-dez. 2006. Disponível em: https://www.scielo.br/j/psoc/a/pLKXBPGnzmmHJdnYGf9Sgvf/?lang=pt. Acesso: 29 set. 2019.

COSTA, Teresinha. Psicanálise com crianças. 3. ed. Rio de Janeiro: Zahar, 2010.

FELÍCIO, Tatiane. Os sentidos do território: o uso de imagens como estratégias de in(ter)venção com jovens no programa de medidas socioeducativas. 2017. Trabalho de Conclusão de Curso (Bacharelado em Psicologia) - Faculdade Guilherme Guimbala, Joinville, 2017.

FLORENTINO, Bruno Ricardo Bérgamo; MELO, Walter. A inserção da Psicologia no Sistema Único de Assistência Social: notas introdutórias. Gerais: Revista Interinstitucional de Psicologia, Belo Horizonte, v. 10, n. 1, p. 3-12, jan-jun. 2017. Disponível em: http://pepsic.bvsalud.org/scielo.php?script=sci_arttext\&pid=S198382202017000100002\&lng=pt\&nrm=iso. Acesso em: 23 ago. 2019.

GOMES, Allan Henrique; ANDRADE, Letícia de; MAHEIRIE, Kátia. A experiência de ser trabalhador na assistência social: imagens implicadas com o campo da desigualdade social. Pesquisas e Práticas Psicossociais, São João del Rei, v. 12, n. 3, p. 1-18, set-dez. 2017. Disponível em: http://www.seer.ufsj.edu.br/index.php/revista_ppp/article/view/2658/1757. Acesso em: 23 ago. 2019.

KOSER, Daiane; SOUZA, Fabiana Patricia de; MULLER, Juliana Maria Soares. Frutos do abandono: as concepções de crianças e adolescentes sobre estar em abrigo. 2007. Trabalho de Conclusão de Curso (Bacharelado em Psicologia) - Faculdade Guilherme Guimbala, Joinville, 2007.

LEONCIO, Wadad Ali Hamad. Consultas terapêuticas de crianças abrigadas e seus pais: uma investigação dos vínculos familiares. 2009. Tese (Doutorado em Psicologia) Universidade de São Paulo, São Paulo, 2009.

MALVASI, Paulo Artur. Entre a frieza, o cálculo e a "vida loka": violência e sofrimento no trajeto de um adolescente em cumprimento de medida socioeducativa. Saúde e Sociedade, 
São Paulo, v. 20, n. 1, p. 156-170, 2011. Disponível em:

https://www.scielo.br/j/sausoc/a/BttBH7JhTDSBhBJ5yxz8Y3K/abstract/?lang=pt. Acesso: 29 set. 2019.

MARTINS, Karla Patrícia Holanda; MATOS, Tereza Gláucia Rocha; MACIEL, Regina Heloisa Mattei de Oliveira. Formação em psicologia e as novas demandas sociais: relato dos egressos da Universidade de Fortaleza. Revista Mal-estar e Subjetividade, Fortaleza, v. 9, n. 3, p. 1023-1042, set. 2009. Disponível em:

https://periodicos.unifor.br/rmes/article/view/1673/3639. Acesso em: 06 jun. 2019.

MOTTA, Roberta Fin; SCARPARO, Helena Beatriz Kochenborger. A Psicologia na Assistência Social: transitar, travessia. Psicologia \& Sociedade, Belo Horizonte, v. 25, p. 230-239, 2013. Disponível em:

https://www.scielo.br/j/psoc/a/pQSDqDm77j3V4L7YcZFFK5S/?lang=pt. Acesso em: 23 ago. 2019.

NEVES, Maria Gabriela. Rel(ações) étnico-raciais: perspectivas de trabalhadores do Sistema Único de Assistência Social de Joinville. 2017. Trabalho de Conclusão de Curso (Bacharelado em Psicologia) - Faculdade Guilherme Guimbala, Joinville, 2017.

OLIVEIRA, Isabel Fernandes de et al. A prática psicológica na proteção social básica do SUAS. Psicologia \& Sociedade, Florianópolis, v. 23, p. 140-149, 2011. Disponível em: https://www.scielo.br/j/psoc/a/WHD3gGP7zZwBpgF9Kvpqhrz/abstract/?lang=pt. Acesso em: 29 ago. 2019.

OLIVEIRA, Isabel Fernandes de; AMORIM, Keyla Mafalda de Oliveira. Psicologia e política social: o trato da pobreza como "sujeito". Psicologia Argumento, Curitiba, v. 30, b. 70, p. 559-566, jul-set. 2012. Disponível em:

https://periodicos.pucpr.br/index.php/psicologiaargumento/article/view/20519/pdf. Acesso em: 23 ago. 2019.

OLIVEIRA, Marcus Vinicius de. A ação clínica e os espaços institucionais das políticas públicas: desafios éticos e técnicos. In: CONSELHO FEDERAL DE PSICOLOGIA. Ano da psicoterapia: textos geradores. Brasília, 2009. p. 106-130.

PEREIRA, Daniel Luciano; PORSCH, Tatiana Benck. A trajetória dos sujeitos até sua inserção como pais sociais nas instituições de acolhimento. 2011. Trabalho de Conclusão de Curso (Bacharelado em Psicologia) - Faculdade Guilherme Guimbala, Joinville, 2011.

RAUPPY, Fabiano Maury; BEUREN, Ilse Maria. Metodologia da Pesquisa Aplicável às Ciências Sociais. In: BEUREN, Ilse Maria et al. Como elaborar trabalhos monográficos em contabilidade: teoria e prática. 3. ed. São Paulo: Atlas, 2006. p. 76-97.

SANTOS, Giselle Mellissa dos; KROEGER, Isolde. Violência intrafamiliar: um olhar sobre as percepções dos familiares no Serviço de Enfrentamento à Violência, Abuso e Exploração 
Sexual de Crianças e Adolescentes no município de Joinville. 2011. Trabalho de Conclusão de Curso (Bacharelado em Psicologia) - Faculdade Guilherme Guimbala, Joinville, 2011.

SÁ-SILVA, Jackson Ronie; ALMEIDA, Cristóvão Domingos de; GUINDANI, Joel Felipe. Pesquisa documental: pistas teóricas e metodológicas. Revista Brasileira de História \& Ciências Sociais, n. 1, p. 1-15, jun. 2009. Disponível em: https://periodicos.furg.br/rbhcs/article/view/10351/pdf. Acesso em: 14 maio 2019.

SAWAIA, Bader Burihan. Psicologia e desigualdade social: uma reflexão sobre liberdade e transformação social. Psicologia \& Sociedade, Florianópolis, v. 21, n. 3, p. 364-372, dez. 2009. Disponível em:

https://www.scielo.br/j/psoc/a/SNXmnP85p4XsKmsrWgbgtpr/?lang=pt. Acesso em: 23 ago. 2019.

SAWAIA, Bader Burihan (Org.). As artimanhas da exclusão: análise psicossocial e ética a desigualdade social. 12. ed. Petrópolis: Vozes, 2012.

SENRA, Carmem Magda Ghetti; GUZZO, Raquel Souza Lobo. Assistência social e psicologia: sobre as tensões e conflitos do psicólogo no cotidiano do serviço público.

Psicologia \& Sociedade, Belo Horizonte, v. 24, n. 2, p. 293-299, ago. 2012. Disponível em: https://www.scielo.br/j/psoc/a/rdzMc6m5DDMvwhpy6kfx38L/abstract/?lang=pt. Acesso em: 29 ago. 2019.

SIEWERT, Clarice Steil; SIEGLE, Raquel. De casa para a rua... e da rua, para onde? A história de um menino abrigado. 2005. Trabalho de Conclusão de Curso (Bacharelado em Psicologia) - Faculdade Guilherme Guimbala, Joinville, 2005.

SILVEIRA, Adriana Ferreira Amorim da; REINKE, Carla Simone. O olhar pré-adolescente e do adolescente institucionalizado sobre família, abrigo, adoção e suas expectativas de futuro. 2009. Trabalho de Conclusão de Curso (Bacharelado em Psicologia) - Faculdade Guilherme Guimbala, Joinville, 2009.

SPINK, Peter. Análise de documentos de domínio público. In: SPINK, Mary Jane (Org.). Práticas discursivas e produção de sentidos no cotidiano. Rio de Janeiro: Centro Edelstein de Pesquisas Sociais, 2013. p. 100-126.

WITT, Camila et al. Relatório de Estágio Curricular Supervisionado: Práticas de Ensino de Psicologia e Processos Educacionais. 2018. Relatório (Bacharelado em Psicologia) Faculdade Guilherme Guimbala, Joinville, 2018.

YAMAMOTO, Oswaldo Hajime; OLIVEIRA, Isabel Fernandes de. Política Social e Psicologia: uma trajetória de 25 anos. Psicologia: Teoria e Pesquisa, Brasília, v. 26, n. spe, p. 9-24, 2010. Disponível em:

https://periodicos.unb.br/index.php/revistaptp/article/view/17502/16418. Acesso em: 19 jun. 2019. 
ZANIANI, Ednéia José Martins; BOARINI, Maria Lúcia. Infância e vulnerabilidade: repensando a proteção social. Psicologia \& Sociedade, Belo Horizonte, v. 23, n. 2, p. $272-$ 281, 2011. Disponível em: https://www.scielo.br/j/psoc/a/kjWV8JjMzPQMSL6vjh8vdRr/?lang=pt\&format=pdf. Acesso em: 29 set. 2019.

\section{NOTAS:}

${ }^{1}$ Iremos nos referir à classe profissional pelo substantivo feminino, tendo em vista que $89 \%$ da psicologia brasileira é composta por mulheres (CFP, 2013).

${ }^{2}$ Iremos nos referir como 'campo educacional' os relatórios do estágio realizados no quarto ano da graduação. Esse estágio sofreu modificações no decorrer dos anos: de 2003 a 2010 denominava-se estágio de Psicologia Escolar; de 2011 a 2015, estágio de Psicologia Educacional e Comunitária; e por fim, após a implantação da licenciatura, que passou a vigorar no curso de psicologia a partir de 2013 em razão da Resolução ${ }^{\circ} 5$ de 15 de Março de 2011, uma nova modalidade denominada Práticas de Ensino de Psicologia e Processos Educacionais inicia com o quarto ano de 2016.

${ }^{3}$ Em razão do sigilo da/o pesquisa/estágio muitos documentos não nomearam a instituição, mas foi possível indicar pela caracterização do espaço, profissionais e público atendido.

Recebido em: 29/06/2020

Aprovado em: 15/09/2020 